\title{
Dynamic Characteristics of Small Diameter End Mill
}

\author{
Takashi MATSUMURA ${ }^{1}$, Yasuaki MIYAHARA ${ }^{2}$, and Takenori ONO ${ }^{3}$ \\ ${ }^{1}$ Department of Mechanical Engineering, Tokyo Denki University, Japan, tmatsumu@cck.dendai.ac.jp \\ ${ }^{2}$ Graduate school of Engineering, Tokyo Denki University, Japan \\ ${ }^{3}$ Graduate School of Advanced Science and Technology, Tokyo Denki University, Japan
}

\begin{abstract}
:
The dynamic response of small diameter tools is measured to simulate the dynamic cutting process in micro-scale milling. The inclined ball end mills are excited with measuring the exciting force on the vibration generator. The modal parameters are estimated with changing the cutter axis inclination and the overhang of the tool. A vibration model is presented to show that the vibration is subjected in the radial direction of the small diameter tool. The dynamic cutting process is simulated to show the effect of the spindle speed on the tool displacement based on the estimated modal parameters.
\end{abstract}

Keywords: Milling, Ball end mill, Dynamic response, Simulation, Vibration test

\section{Introduction}

Recent machine shops in the mold manufacturing industries have been using many small diameter end mills. The micro millings have also applied to micro fabrication on devices. The cutting force in the milling process changes during a cutter rotation due to engagement and disengagement of the edges. Therefore the interrupted cutting induces the displacement of the tool with the vibration. The influence of the tool displacement on the machining accuracy and the surface finish is critical especially in machining with the small diameter end mills. The displacement with the vibration in the cutting processes should be considered to determine the cutting conditions. The dynamic response of the tool is required in the simulation of the dynamic cutting process. Many researchers have interested in the dynamic cutting process so far. Tobias analyzed the stability of the cutting process based on the coefficient of viscous damping [1]. Merritt presented the stability chart based on the block diagram [2]. Tlusty et al. analyzed the stability of the cutting process with the mode coupling [3]. However, the critical study has been left on the stability analysis in machining with small diameter tools because of its difficulty in measurement of their dynamic response. The dynamic response generally can be measured by the impulse test. However, the impulse test cannot be applied to the measurement of the small diameter end mills due to their breakage. Other approaches have been required for measurement of the dynamic response.

Machine shops have also performed free form machining on multi-axis controlled machine tools. The cutter axis inclination should be evaluated to improve the cutting process. Generally the cutter axis inclination is applied to machining with the ball end mill because the cutting velocity is low to deteriorate the surface finish at bottom of the cutter. Lazoglu and Liang presented the force model of the ball end mill with the cutter axis inclination [4]. Zhu et al. discussed the force model with the inclined ball end mill associated with the change of the surface profile [5]. Liu et al. discussed the effect of the tool inclination on the machined surface [6]

This study measures the dynamic characteristics of the small diameter ball end mills with the cutter axis inclination. The vibration tests are performed to measure the exciting load with changing the frequency of the tool displacement on a vibration generator. The modal parameters in the vibration equation, then, are estimated in the dynamic response. A model is also presented to estimate the dynamic response in the radial direction of the tool. The simulation is tried to show the dynamic cutting processes using the estimated modal parameters. Many studies have been presented the force models to simulate the cutting processes in the milling operations [7]. Force models based on the cutting coefficient have been presented with associating the cutting force with the cutting thickness in the milling process [8][9]. The model was applied to the simulation of the dynamic cutting process with the vibration of the tool. Usui et al. presented another model based on the cutting energy to predict the cutting force with the chip flow direction [10]. This study applies their force model to simulation of the milling process. The chip flow is interpreted as a piling up of the orthogonal cuttings, where the chip flow direction can be determined to minimize the cutting energy. The effect of the spindle speed on the tool vibration can be evaluated in the simulation based on the dynamic response measured in the vibration test.

\section{Vibration Test}

\subsection{Experiment}

The dynamic characteristics of the small diameter tool are measured with the vibration generator as shown in Fig. 1. The vibration tests are performed to measure the exciting load with changing the frequency of the tool displacement. The $3 \mathrm{~mm}$ diameter end mills are mounted on a spindle with the cutter axis inclination at angles of 30 and $45 \mathrm{deg}$. The milling tool is clamped on the spindle 


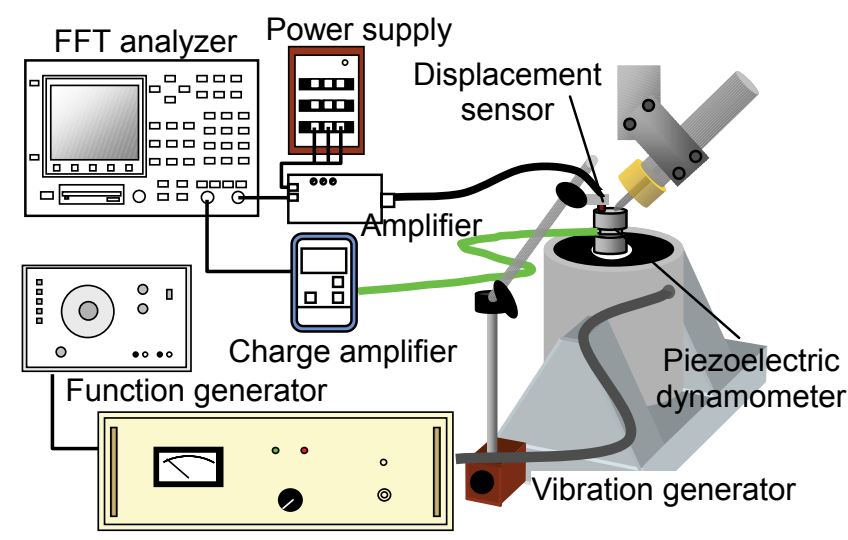

Figure 1: Vibration test.

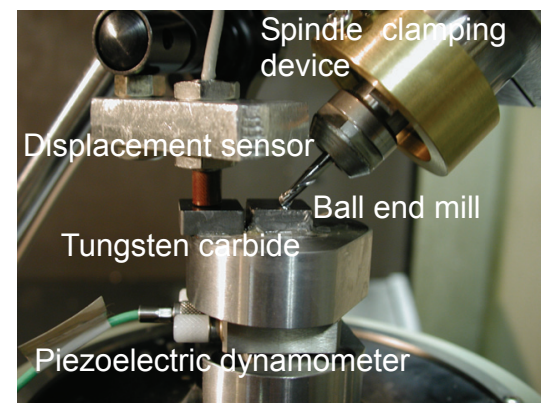

Figure 2: Ball end mill on excited table.

with changing the overhang from the collet. Figure 2 shows the ball end mill made of tungsten carbide on the excited table. The edge is clamped with the preload on the excited table made of tungsten carbide to ignore the effect of elastic deformation of the table. The preload is given by moving the tool down in a height of $0.02 \mathrm{~mm}$ after its contact with the table. The exciting load can be measured at the given displacement with piezoelectric dynamometer, which is mounted under the excited table. The displacement of the table is controlled by the sinusoidal wave generator. Because the vibration generator cannot be driven with feedback control, the displacement of the table is measured with the sensor, which measures the distance between the sensor head and the table with the eddy current. The FFT analyzer calculates the compliance with measuring the power spectrum of the load and that of the displacement. The modal parameters in the vibration equation, then, are estimated in the dynamic response.

\subsection{Dynamic response}

Figure 3 shows a result of the compliances with the vibration frequencies, where the inclination angle of the cutter axis is $30 \mathrm{deg}$; and the overhang of the end mill from the collet is $15 \mathrm{~mm}$. The frequency is changed from 0 to $1000 \mathrm{~Hz}$. The figure shows the dynamic response around the natural frequency. The natural frequency is estimated to be $335 \mathrm{~Hz}$ based on the peak of the compliance $G_{\varphi}$ in Fig. 3. Figure 4 shows the natural frequencies estimated in the compliances with changing the overhang and the inclination angle of the cutter axis. The natural frequency decreases with increasing the overhang. Because the lower stiffness generally shows the lower natural frequency, the

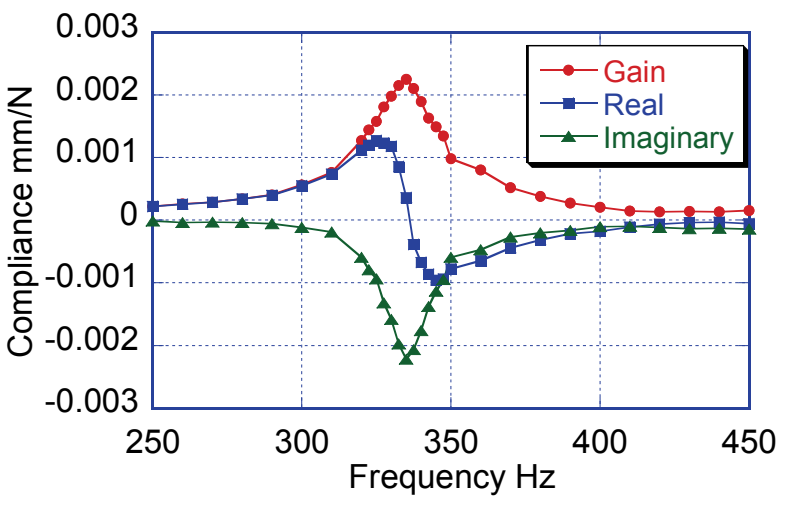

Figure 3: Compliance.

Overhang, 15mm; cutter axis inclination, $30 \mathrm{deg}$.

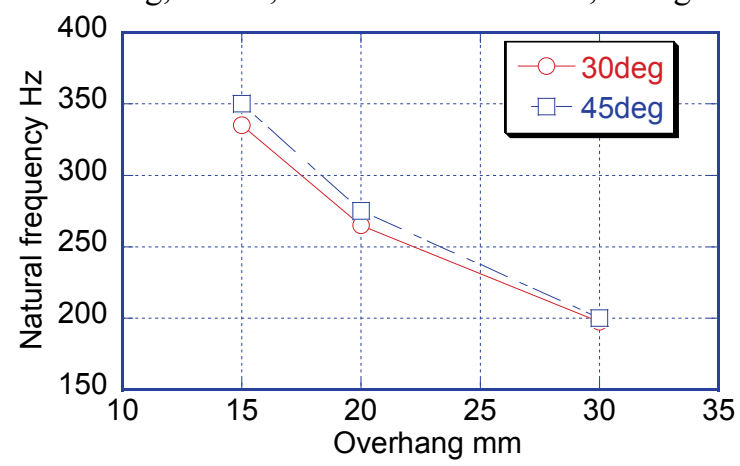

Figure 4: Change of natural frequency with overhang.

stiffness is low at a large overhang. Because the stiffness of the tool mainly depends on the aspect ratio, which is the ratio of the overhang from the collet to the diameter of the tool, the natural frequency does not change with the cutter axis inclination as shown in Figure 4.

The modal parameters in the following equation are estimated in the measured compliance of Fig. 3:

$$
m \frac{d^{2} x}{d t^{2}}+c \frac{d x}{d t}+k x=F
$$

where $x$ and $F$ are the displacement and the load. The modal parameters: $m, c$, and $k$ are the equivalent mass, the coefficient of viscous damping, and the stiffness. Figure 5 shows the modal parameters with the overhang and the cutter axis inclination. The modal parameters are estimated to minimize the discrepancy between the measured and the calculated compliance with adjusting the modal parameters. The compliance $G_{\varphi}$ of the tool inclined at the angle $\varphi$ can be calculated with the angular frequency $\omega$ as follows:

$$
\left\{\begin{array}{l}
G_{\varphi}(\omega)=\frac{1}{k} \frac{1}{\sqrt{\left\{1-\left(\omega / \omega_{n}\right)^{2}\right\}^{2}+\left(2 D \omega / \omega_{n}\right)^{2}}} \\
\omega_{n}=\sqrt{\frac{k}{m}} \\
D=\frac{c}{2 \sqrt{m k}}
\end{array}\right.
$$

where $\omega_{n}$ and $D$ are the natural frequency and the damping ratio respectively. The equivalent mass in the vibration system does not change remarkably with the 


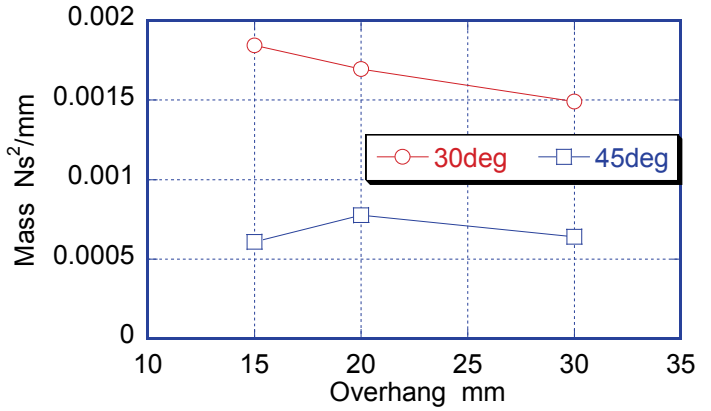

(a) Equivalent mass

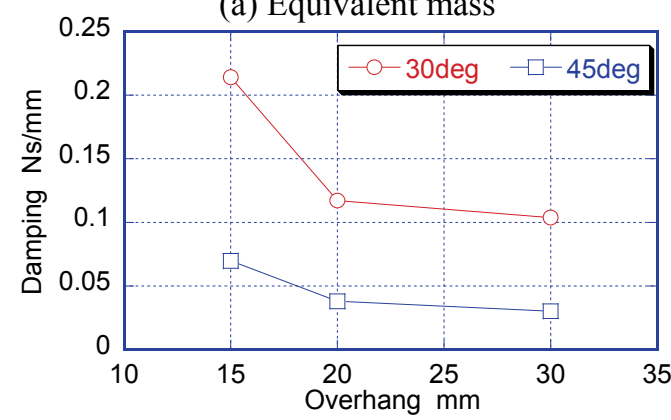

(b) Coefficient of damping

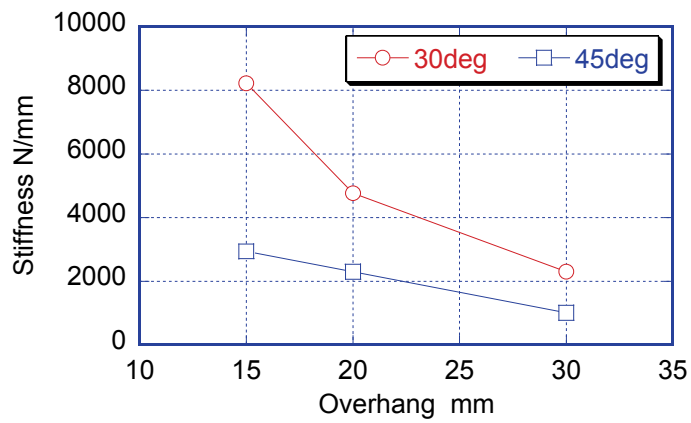

(c) Stiffness

Figure 5: Modal parameters.

overhang of the tool in Fig. 5. However, the damping coefficient and the stiffness reduce with increasing the overhang of the tool. The damping and the stiffness are also low when the inclination angle of the cutter axis is large.

\subsection{Vibration model of the inclined tool}

A vibration model is presented to estimate the dynamic response of a small diameter ball end mill with the cutter axis inclination. Figure 6 shows the displacement and the load in the vibration tests. If it is assumed that the tool displacement is subjected in the direction of the tool radius, the load and the displacement in the vibration direction can be transferred to the component of the tool radial direction as follows:

$$
\left\{\begin{array}{l}
F=F_{\varphi} \sin \varphi \\
\delta=\frac{\delta_{\varphi}}{\sin \varphi}
\end{array}\right.
$$

where $\varphi$ is the inclination angle of the cutter. $\delta_{\varphi}$ and $F_{\varphi}$ are the displacement and the load in the vibration direction; and $\delta$ and $F$ are those in the tool radial direction. Therefore, the compliance $G$ in the tool radial direction can be given by:

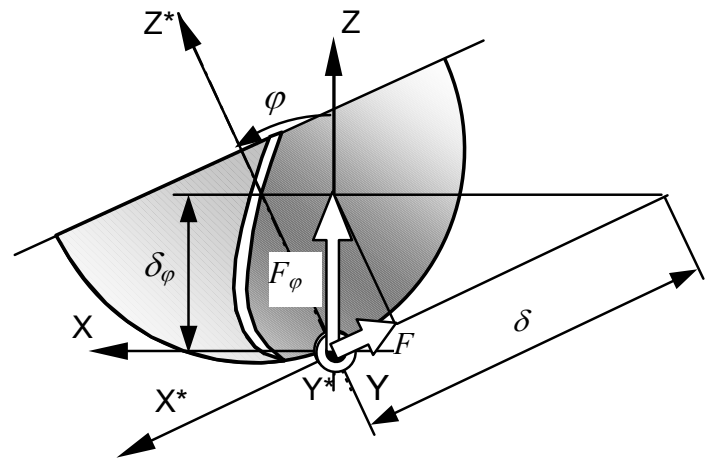

Figure 6: Vibration model.

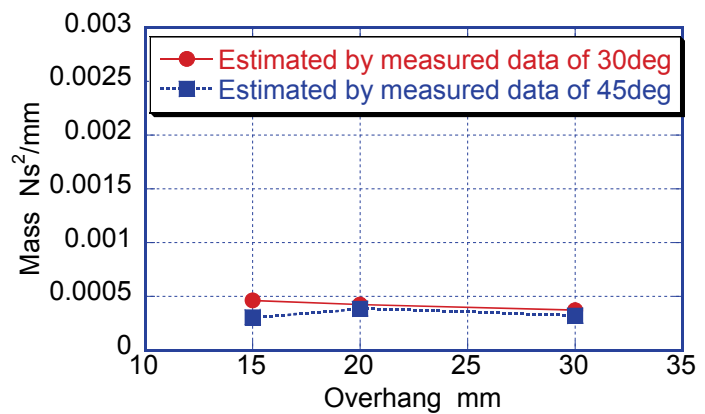

(a) Equivalent mass

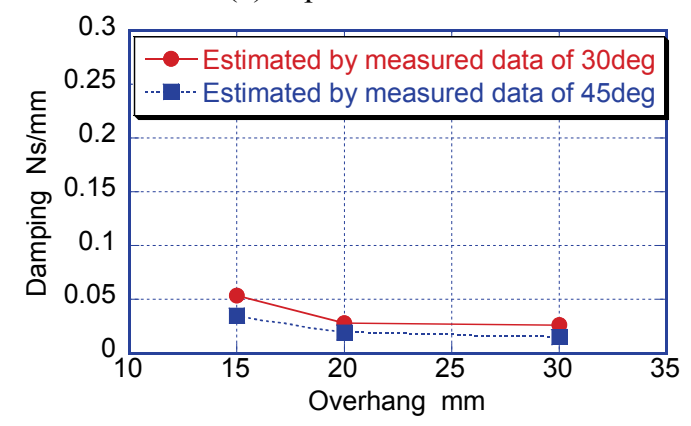

(b) Coefficient of damping

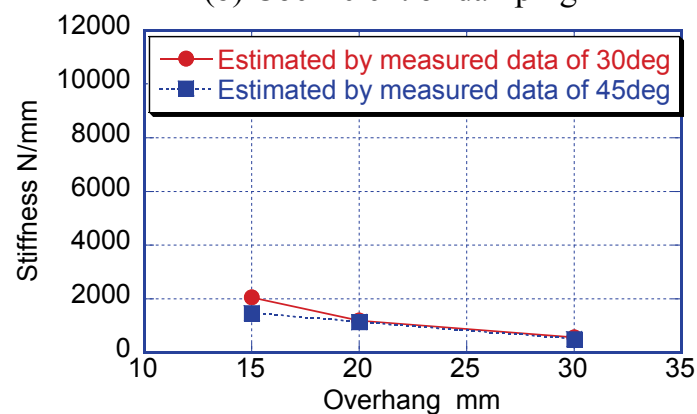

(c) Stiffness

Figure 7: Modal parameters in the radial direction of the tool.

$$
G=\frac{G_{\varphi}}{\sin ^{2} \varphi}
$$

$G_{\varphi}$ is the compliance in the vibration direction, which can be measured in the vibration test as shown in Fig. 3. The modal parameters in the tool radial direction can be estimated after transferring $G_{\varphi}$ to $G$ in Eq. (4). Figure 7 shows the modal parameters in the tool radial direction with the overhangs and the cutter axis inclinations. The modal parameters determined by an inclination angle of $45 \mathrm{deg}$ are almost the same as those of an angle of $30 \mathrm{deg}$. 


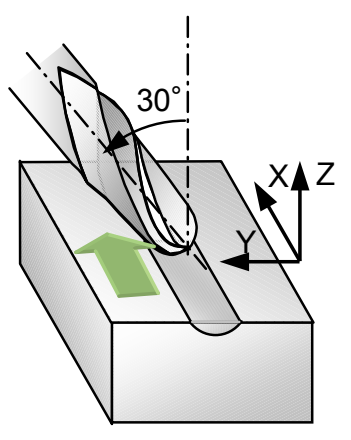

Figure 8: Cutting process.

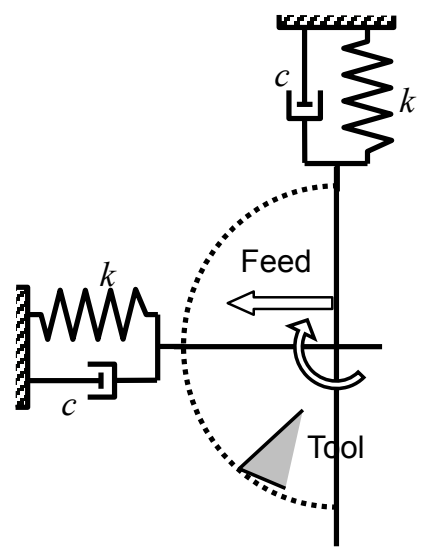

Figure 9: Vibration system.

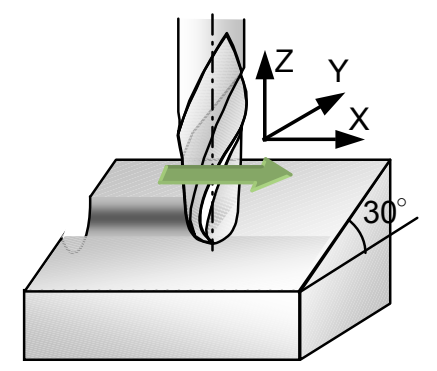

Figure 10: Equivalent process to Fig. 8.

It proves that the tool mainly excited in the radial direction of the tool. Although the effect of the axial stiffness should be considered strictly, it can be expected to apply the presented approximate model to the estimation of the dynamic response of the small diameter tool. The modal parameters can be estimated with the other cutter axis inclinations when the compliances are measured in a vibration tests with a cutter axis inclination.

\section{Simulation of Dynamic Cutting Process}

\subsection{Vibration model}

The dynamic cutting process is simulated in machining of $0.45 \%$ carbon steel with the inclined ball end mill at an angle of $30 \mathrm{deg}$ as shown in Fig. 8. The tool diameter is $3 \mathrm{~mm}$; and the tool material is tungsten carbide. The displacement and the velocity of the tool are subjected in the radial direction of the tool based on the results in the previous chapter. The simulation is here performed with assuming the orthogonal two degrees of freedom in the vibration system in the plane containing the tool radius as shown in Fig. 9. Although the modal parameters in each vibration system change with the excited direction in the

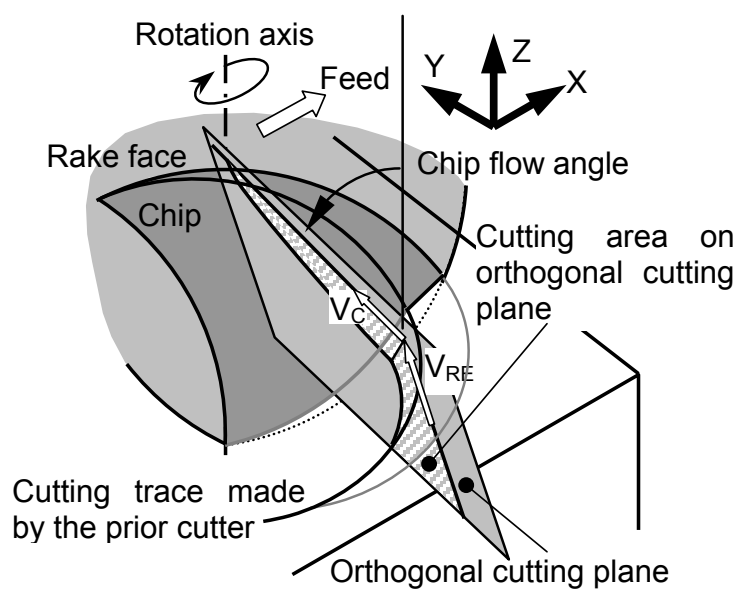

Figure 11: Chip flow model.

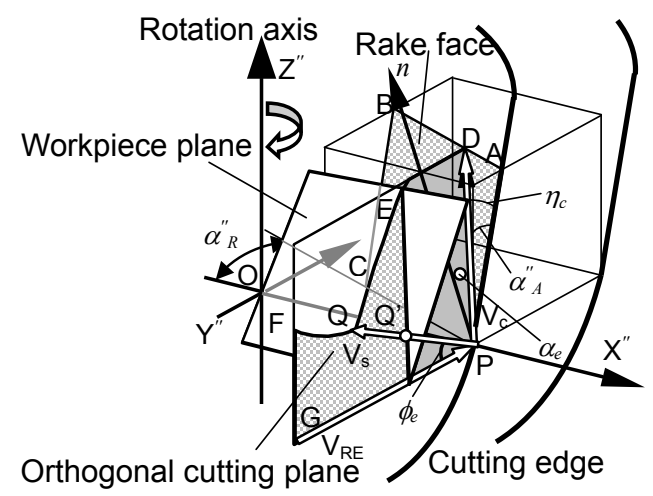

Figure 12: An orthogonal cutting in chip flow model.

vibration tests, the same parameters, which are estimated in the previous chapter, are applied in both of the vibration systems as a trial.

\subsection{Force model}

The cutting process in Fig. 8 is simulated to predict the cutting force with the tool displacement. Three components of the cutting force are calculated in the direction of each axis. In the simulation, the cutting process can be regarded as the equivalent process in Fig. 10, where the ball end mill machines the workpiece inclined at the angle $\theta$ in the vertical plane with respect to the feed direction of the cutter.

Because the detail approaches are described in Reference [11] and [12], this paper briefly summarizes the simulation. Figure 11 shows a chip flow process in milling with a ball end mill. The chip flow model is interpreted as a piling of orthogonal cuttings in the planes containing the cutting velocities $V_{R E}$ and the chip flow velocities $V_{c}$, where the chip is assumed to flow without plastic deformation between each plane. The force model divides a cutting edge into small segments to consider the change of the edge shape along the cutting edge. When the chip flow angle is assumed, the orthogonal cutting models can be made on the divided edge segments using the following data:

$$
\left.\begin{array}{l}
\phi=f\left(\alpha, V, t_{1}\right) \\
\tau_{s}=g\left(\alpha, V, t_{1}\right) \\
\beta=h\left(\alpha, V, t_{1}\right)
\end{array}\right\}
$$




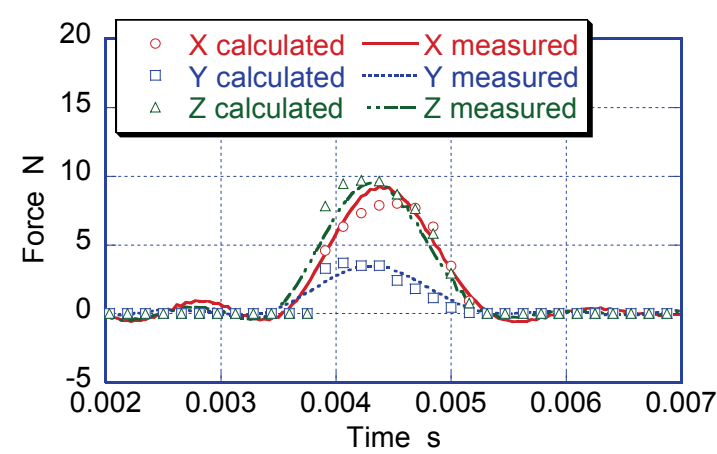

Figure 13: Simulation of cutting process.

Cutting conditions; material cut, $045 \%$ carbon steel; spindle speed, 6000rpm; depth of cut in $Z$ axis, $0.1 \mathrm{~mm}$; feed rate, $120 \mathrm{~mm} / \mathrm{min}$; and tool inclination, $30 \mathrm{deg}$.

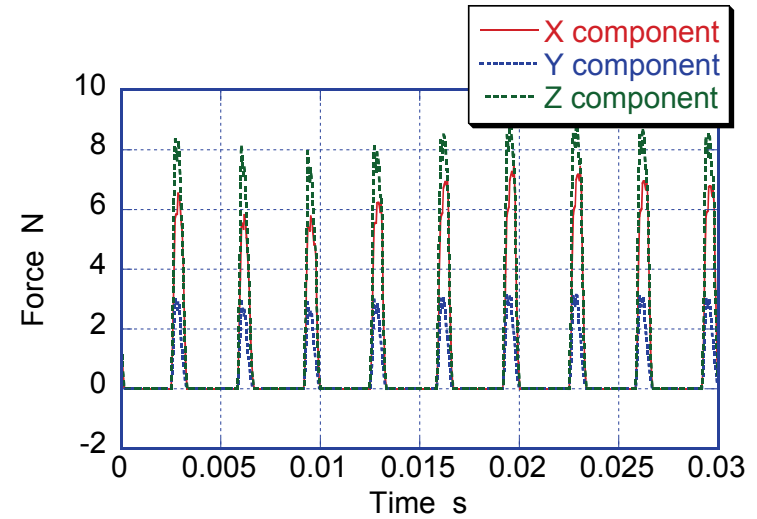

Figure 14: Cutting process with tool displacement. Cutting conditions; material cut, 045\% carbon steel; spindle speed, 9000rpm; depth of cut in $\mathrm{Z}$ axis, $0.1 \mathrm{~mm}$; feed rate, $180 \mathrm{~mm} / \mathrm{min}$; tool inclination, $30 \mathrm{deg}$; and overhang, $15 \mathrm{~mm}$.

where $\phi, \tau_{s}$ and $\beta$ are the shear angle, the shear stress on the shear plane and the friction angle. $\alpha, V$ and $t_{l}$ are the rake angle, the cutting velocity and the undeformed chip thickness. Figure 12 shows the orthogonal cutting model at the point $\mathrm{P}$ in the plane containing the cutting velocity and the chip flow velocity in the coordinate system $X "-Y "-Z$ ". The plane PABC shows the rake face of the cutter inclined at the radial rake angle $\alpha_{\mathrm{R}}$ " and the axial rake angle $\alpha_{\mathrm{A}}$ " with respect to the direction of the cutting velocity, which is the sum of the rotational speed and the feed rate. The plane PDEFG is the orthogonal cutting model at the point $\mathrm{P}$, which is divided into the inside and the outside of the material. When the end point Q of the shear plane made by the orthogonal cutting data is outside of the workpiece and the edge tip $\mathrm{P}$ is inside of the workpiece, the shear energy is calculated with estimating the length of the shear plane PQ', where $Q^{\prime}$ is the intersection of $\mathrm{PQ}$ and workpiece plane.

Then the cutting energy, which is the sum of the shear energy on the shear planes and the friction energy on the rake faces, can be calculated at the assumed chip flow angle. The chip flow direction, then, are determined to minimize the cutting energy. The cutting force can be calculated in the cutting model giving the minimum cutting energy.

Figure 13 shows an example of the analysis results in machining of $0.45 \%$ carbon steel with carbide tool, where

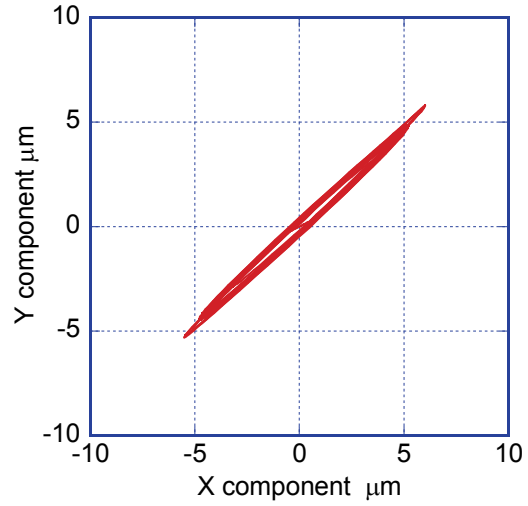

Figure 15: Trajectory of tool axis. Cutting conditions are the same as those in Fig. 14.

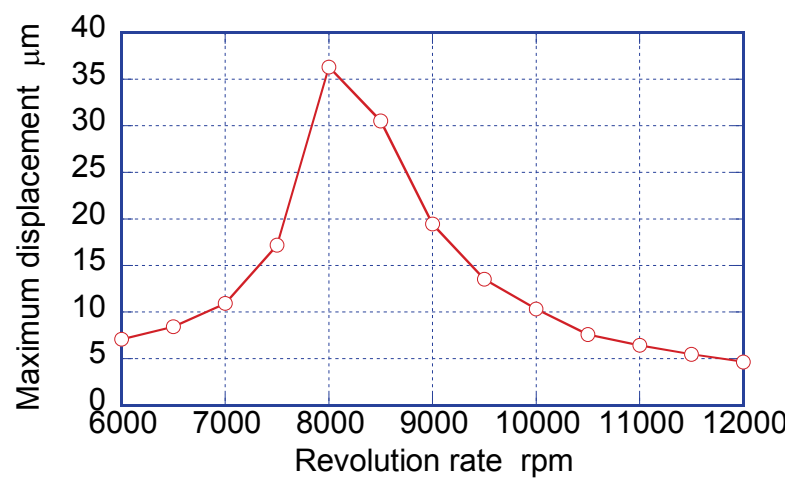

Figure 16: Maximum displacement with spindle speed. Cutting conditions; material cut, 045\% carbon steel; depth of cut in $Z$ axis, $0.1 \mathrm{~mm}$; feed rate per edge, $0.01 \mathrm{~mm} /$ edge; tool inclination, $30 \mathrm{deg}$; and overhang, $20 \mathrm{~mm}$.

the components of the cutting force is shown in the directions as shown in Fig. 8. The analysis result designated by the symbols agrees with the measured force shown by the solid line.

\subsection{Dynamic cutting process}

The displacement and the velocity in each mode direction can be given independently by Eq. (1) in the orthogonal vibration system, where Eq. (1) is numerically solved by Runge-Kutta method. The components in each mode direction are summed to the resultant displacement and the resultant velocity of the tool. The tool displacement has influence on the undeformed chip thickness. Because the orthogonal cuttings piled up in the chip flow model depend on Eq. (5) as a function of the cutting velocity, the change of the velocities induced by the vibration velocity has also influence on the cutting models. Therefore the cutting force changes with the displacement and the velocity of the tool. Figure 14 shows the cutting force with the cutting time, where the simulation is performed in 5 rotations of the cutter, where the tool is inclined at an angle of 30deg; the overhang of the tool is $15 \mathrm{~mm}$; the spindle speed is $9000 \mathrm{rpm}$; the depth of cut in the $\mathrm{Z}$ direction is $0.1 \mathrm{~mm}$; and the feed rate is $180 \mathrm{~mm} / \mathrm{min}$. The modal parameters in the radial direction determined by the measured compliance of $15 \mathrm{~mm}$ overhang and $30 \mathrm{deg}$ 
cutter axis inclination in Fig. 7 are used in the simulation. The cutting force changes with rotation of the cutter. Figure 15 shows the trajectory of the center of the tool axis in the moving coordinate system at the feed rate, where the origin shows the position of the cutter axis without the displacement. According to the result in Fig. 15 , the machining error is around $\pm 5 \mu \mathrm{m}$ though the tool displacement during air cutting is shown in the figure.

Figure 16 shows the maximum displacements in the simulation with the spindle speeds, where the tool is inclined at an angle of $30 \mathrm{deg}$ and the depth of cut in the $\mathrm{Z}$ direction is $0.1 \mathrm{~mm}$. The feed rate changes to keep the same feed rate per edge of $0.01 \mathrm{~mm} /$ edge with the spindle speed. The overhang of the tool is $20 \mathrm{~mm}$, which is different from that of the analysis in Fig. 14. Because the displacement associated with the natural frequency of the tool and the period of the cutting force working as the excited load, the maximum displacement depends on the spindle speed. The result in Fig.16 makes it clear that the undesirable spindle speed is $8000 \mathrm{rpm}$. The dynamic simulation shows the direction of determination of the cutting conditions with the estimated dynamic response.

\section{Conclusion}

This paper presented the measurement of the dynamic response on the vibration generator for the stability analysis in the cutting process with the inclined ball end mill. The excitation load is measured with the piezoelectric dynamometer under the excited table. The tool is mounted on the tungsten carbide with the excited table. The displacement of the vibration is monitored with the sensor, which measures the distance between the sensor head and the table with the eddy current. The vibration tests are performed with changing the overhang and the cutter axis inclination. The natural frequency depends on the overhang of the tool associated with the stiffness. However the natural frequency does not change with the inclination angle. The stiffness and the coefficient of viscous damping decrease with increasing the overhang and the inclination angle of the tool. A vibration model is presented to estimate the vibration system in the radial direction of the tool with assuming the tool axis mainly moves in the plane containing the cutter radius. The dynamic cutting process is simulated with predicting the movement of the cutter axis during machining based on the estimated modal parameters in the radial direction of the tool, where the simulation is performed with assuming the orthogonal two degrees of freedom in the vibration system. The cutting force in the dynamic cutting process can be predicted in the force model based on the minimum cutting energy, which makes the chip flow model with piling up the orthogonal cuttings. The spindle speed can also be determined with simulating the change of the maximum displacement.

\section{References}

[1] Tobias, S. A., 1965, Machine-Tool Vibration, Blackie, London.

[2] Merritt, H. E., 1965, Theory of Self-Excited Machine-Tool Chatter, Transactions of ASME,
Journal of Engineering for Industry, Vol. 87, pp. 447-454.

[3] Koenigsberger, F. and Tlusty, J., 1970, Machine Tool Structure, Vol. 1, Pergamon Press, England.

[4] Lazoglu, I., Liang, S. Y., 2000, Modeling of Ball-End Milling Forces with Cutter Axis Inclination, Transactions of ASME, Journal of Manufacturing Science and Engineering, Vol. 122, pp.3-11.

[5] Zhu, R., Kapoor, S. G., DeVor, R. E., 2001, Mechanistic Modeling of the Ball End Milling Process for Multi-Axis Machining of Free-Form Surfaces, Transactions of ASME, Journal of Manufacturing Science and Engineering, Vol. 123, pp.369-379.

[6] Liu, X., Soshi, M., Sahasrabudhe, A., Yamazaki, K, and Mori, M, 2004, A Geometrical Simulation System of Ball End Finish Milling Process and Its Application for the Prediction of Surface Micro Features, Transactions of ASME, Journal of Manufacturing Science and Engineering, Vol. 128, pp.74-85.

[7] Smith, S. and Tlusty, J., 1991, An Overview of Modeling and Simulation of the Milling Process, Transactions of ASME, Journal of Engineering for Industry, Vol. 113, pp.169-175.

[8] Yucesan, G. and Altintas, Y., 1996, Prediction of Ball End Milling Force, Transactions of ASME, Journal of Engineering for Industry, Vol. 118, pp.95-103.

[9] Bayoumi, A. E., Yucesan, G., and Kendall, L. A., 1994, An Analytical Mechanistic Cutting Force Model for Milling Operations: A Theory and Methodology, Transactions of ASME, Journal of Engineering for Industry, Vol. 116, pp.324-330.

[10] Usui, E., Hirota, A. and Masuko, M., 1978, Analytical Prediction of Three Dimensional Cutting Process - Part1 Basic Cutting Model and Energy Approach, Transactions of ASME, Journal of Engineering for Industry, Vol. 100, pp.222-228.

[11] Matsumura, T., Furuki, T. and Usui, E., 2003, Analysis of Cutting Process with Curved-Edge End Mill, Proceedings of the International Conference on Leading Edge Manufacturing in 21st Century, pp. 783-788.

[12] Matsumura, T., Shimada, T. and Teramoto, K., 2005, Analysis of Cutting Process on Machining Centers, Proceedings of the International Conference on Leading Edge Manufacturing in 21st Century, pp. 1093-1098. 